\title{
A comparative study of antioxidant activity, total phenolic and flavonoid contents in different parts of Helicteres isora
} L.

\author{
Amita Jain", Rashmi Ranade, Prem Pritam, Neelu Joshi, Sirisha Lakshmi Vavilala, Ankita Jain \\ School of Biotechnology and Bioinformatics, D.Y. Patil University, Sector No-15, CBD, Belapur, Navi Mumbai, India
}

Email address:

itsamita1975@gmail.com (A. Jain)

\section{To cite this article:}

Amita Jain, Rashmi Ranade, Prem Pritam, Neelu Joshi, Sirisha Lakshmi Vavilala, Ankita Jain. A Comparative Study of Antioxidant Activity, Total Phenolic and Flavonoid Contents in Different Parts of Helicteres isora L.. American Journal of Life Sciences.

Vol. 2, No. 5, 2014, pp. 292-302. doi: 10.11648/j.ajls.20140205.17

\begin{abstract}
Helicteres isora L., commonly known as Indian Screw Tree is a highly valued medicinal plant in South-East Asia. The various phytochemicals like phenols, flavonoids and other antioxidants that impart the medicinal properties in this plant, vary in their composition and concentration in different plant parts. In the present research, the total phenolic content, total flavonoids content and free radical scavenging activity (FRAP and DPPH assay) in fresh and dry sample extracts of leaf, bark, fruit and root of $H$. isora L., prepared in four different solvents (distilled water, ethanol, methanol and acetone) were studied, and their results compared using Pearson's Correlation. The plant extracts were also subjected to RP-HPLC for detection and quantitation of naturally occurring phenolic compounds using six phenolic standards (Gallic acid, Vanillin, Catechol, Ferrulic acid, p-coumaric acid and Caffeic acid). The highest total phenolic content (7.22 mg/g GAE) and FRAP value (64.98 mg/g TE) were observed in aqueous dry root extract. The acetone extract of fresh leaf $(57.08 \mathrm{mg} / \mathrm{g}$ of RE) was found richest in total flavonoids, while the methanolic extract of fresh fruit uniquely exhibited strong free radical scavenging activity as evidenced by the low IC50 value $(34.37 \mathrm{mg} / \mathrm{ml})$ in DPPH assay. The RP-HPLC analysis revealed that Catechol and Gallic acid were most abundantly found phenolic compounds in extracts of $H$. isora $\mathrm{L}$. The total phenolic content showed strong positive correlation with free radical scavenging activity (FRAP and DPPH assays) in both fresh and dry plant parts, suggesting that phenols are the main compounds responsible for the antioxidant activity. The root of $H$. isora $\mathrm{L}$. was found rich in phenolics and antioxidant capacity indicating its strong potential for medicinal use, followed by fruit, leaf and bark.
\end{abstract}

Keywords: Helicteres isora L., Phenols, Flavonoids, DPPH, FRAP, RP-HPLC

\section{Introduction}

Medicinal plants are an important source of antioxidants and active principles. Antioxidant supplements are used to help the human body in reducing oxidative damage by free radicals and active oxygen [1]. In recent years, there has been growing interest in alternative therapies and the therapeutic use of natural products, especially those derived from plants [2-4] and also due to the growing recognition that the natural products are non-toxic, have lesser side effects and are easily available at affordable prices [5].

Helicteres isora L. is a large shrub of the family Sterculiaceae, which occurs in dry forests throughout central and western India, and some parts of south-east Asia. The plant gained its name as Indian Screw Tree due to the characteristic twisted shape of its fruits. Helicteres isora L. has been used traditionally as a herbal drug for treatment of many ailments throughout south-east Asia since ancient times, in Ayurvedic, folk and tribal medicines [6].

All parts of this plant leaf, bark, fruit and root have been used to treat different diseases. The fruits of this plant are astringent, stomachic, vermifugal, vulnerary, used in griping of bowels and flatulence in children [7] as well as have antispasmodic effect [8]. Powdered dry fruits have been used in traditional medicine for treatment of various skin diseases and disorders like dermatitis, eczema, acne etc. It is used as antipyretic, anti-diarrheal, anti-dysenteric, anti-helmintic for tapeworms and as a tonic after childbirth. The root juice is claimed to be useful in treating cough, asthma, diabetes, emphyenma, intestinal infection, snake bites and a cure for scabies when applied topically [9]. 
Pharmacological studies of different plant parts of $H$. isora based on animal models have revealed many medicinal properties. Bark of $H$. isora has antidiabetic [10], cardiac antioxidant, antiperoxidative potential and hypolipidaemic activities [7] in streptozotocin (STZ) induced diabetic rats. Fruits have revealed hypolipidaemic [1], antioxidant and anticancer properties [11]. Whole plant of $H$. isora is reported to have anticancer [12], antinociceptive activities [13] while roots have hepatoprotective activity [14] against carbon tetrachloride induced liver damage in rats.

Phytochemical analysis of the plant revealed the presence of phenols, flavonoids, alkaloids, glycosides, phytosterols, carotenoids, tannins, neolignans, rosmarinic acid derivatives, betulic acid, daucosterol, tannnins, anthoquinones, sterols, lupeol, $\beta$-sitosterol, $\alpha$ and $\beta$ amyrin, taraxerone and volatile oil in varying concentrations [15-17] isolated three new compounds 49-O-b -D-glucopyranosyl rosmarinic acid, 4,49O-di-b-D-glucopyranosyl rosmarinic acid and 2R-O-(49-O-bD-glucopyranosyl caffeoyl)-3-(4-hydroxyphenyl), lactic acid named as 49-O-b -Dglucopyranosyl isorinic acid together with rosmarinic acid from the fruit of $H$. isora. Flavones such as methyl ether, 7,41-di-o-methyleisoscutellarein i.e. $(5,8-$ dihydroxy-7,41-flavones) along with kaempferol-3-ogalactoside (trifolin) and herbacetin-8-oglucoronide (hibifolin) from the leaves were isolated and characterized [18].

Recently, in vitro studies have been undertaken for scientific and precise determination of its medicinal value, active principles and antioxidant properties. However, the information regarding effect of variable factors such as geographical location, plant part, solvents used and method of extraction on phytochemical content and related antioxidant activity in $H$. isora is very limited. Therefore, in the present study, the different plant parts of $H$. isora were analyzed for their phytoconstituents and antioxidant potential using different in vitro models including RP-HPLC profiling of phenols. The results thus obtained were further compared using correlation analysis. The plant parts were used in fresh as well as dry state, in different solvents to find out which plant part contains maximum antioxidant potential and the solvent for it. The phenolic content of extracts and its relationship with antioxidant activities were also investigated, so as to find the effect of the variable factors on the presence and amount of phytochemicals if any.

\section{Materials and Methods}

\subsection{Plant Material}

The plant parts of Helicteres isora L. were collected from Kolhapur, Maharashtra, India. The plant was authenticated by Dr. Milind Sardesai, Botany Department, Dr. B. R. Ambedkar Marathwara University, Maharashtra, India. Leaves, bark, root and fruits were separated and half of each explant was left to air dry at room temperature for around two weeks for preparation of dry plant extracts, while the rest was used for preparation of fresh extracts.

\subsection{Preparation of Crude Plant Extracts}

The fresh plant material was crushed in liquid nitrogen ($196^{\circ} \mathrm{C}$ ) and dry material was pulverized in blender in order to obtain fine powder. The ground plant tissues were extracted with various solvents like distilled water, ethanol, methanol, acetone using rotavapour. The plant extracts thus prepared were stored at $-20^{\circ} \mathrm{C}$ until further use [19].

\subsection{Chemicals}

Methanol, Acetone, Folin-Ciocalteu reagent, sodium carbonate were purchased from SRL Pvt. Ltd. Mumbai, India; Trolox, Rutin, TPTZ (2,4,6- tripyrolyl-5-triazine), and DPPH were obtained from Sigma-Aldrich Chemical Co. St. Lois, MO, USA; aluminium chloride, gallic Acid, acetic acid were acquired from Molychem, Mumbai, India; ferric chloride from HiMedia Laboratories, Mumbai India; ethanol, HPLC grade water, Phenolic standards, methanol and acetic acid used for RP-HPLC were procured from Merck, Darmstadt, Germany.

\subsection{Qualitative Phytochemical Analysis}

Qualitative tests for detection of presence of alkaloids, glycosides, cardiac glycosides, phenols, flavonoids, tannins, terpenoids, saponins and steroids were performed by using protocols given by Ugochukwu et al [20].

\subsection{Quantitative Phytochemical Assay}

All phytochemical assays were spectrophotometric methods and absorbance at specific wavelengths was taken using a UV spectrophotometer (Shimadzu - Model UV-1700 Pharma spec). For the total phenolic content, total flavonoid content and FRAP assays, the extracts were diluted to $1 \%$ in their respective solvents and these dilutions were used whereas different dilutions of extracts $(10-500 \mathrm{mg} / \mathrm{ml})$ were used for IC50 value determination in DPPH assay. All readings were taken in triplicates and the activities/concentrations of three were averaged to give final value.

\subsubsection{Total Phenolic Content (TPC)}

The TPC was determined by a Spectrophotometric method using $1 \mathrm{~N}$ Folin-Ciocalteu (FC) reagent and 7\% sodium carbonate [19]. The absorbance was recorded at $760 \mathrm{~nm}$. The Phenolic content of each sample had been determined from the standard curve of Gallic Acid. The TPC is expressed as milligrams of Gallic Acid Equivalent per gram of Sample (mg GAE/g).

\subsubsection{Total Flavonoid Content (TFC)}

The total flavonoid content was estimated by spectrophotometric method, which detects the amount of coloured complex formed between the flavonoids and aluminium ions. The sample was reacted with $2 \%$ aluminium chloride and the absorbance was recorded at 368 $\mathrm{nm}$ [21].The flavonoid content of each sample was determined from the standard curve of Rutin. The total 
flavonoid content was expressed as milligrams of Rutin Equivalent per gram of sample (mg RE/g).

\subsubsection{Ferric Reducing Antioxidant Power (FRAP) Assay}

The FRAP assay detects the amount of antioxidants present in the sample quantitatively, based on its ability to reduce $\mathrm{Fe}^{3+}$ to $\mathrm{Fe}^{2+}$. The FRAP reagent was prepared by mixing $50 \mathrm{ml}$ of $0.3 \mathrm{M}$ acetate buffer, $5 \mathrm{ml}$ of $10 \mathrm{mM} \mathrm{TPTZ}$ solution and $5 \mathrm{ml}$ of $20 \mathrm{mM}$ ferric chloride. The three reagents were mixed together and incubated at $37^{\circ} \mathrm{C}$ for 10 min. The samples were reacted with FRAP reagent and the reaction mixture was incubated at $37^{\circ} \mathrm{C}$ for $30 \mathrm{~min}$ [22]. The antioxidant content based on ferric ion reducing ability, was calculated using a standard curve of Trolox at $593 \mathrm{~nm}$. The FRAP value was expressed as milligrams Trolox Equivalent Antioxidant Capacity per gram of sample (mg TEAC/g).

\subsubsection{DPPH Radical Scavenging Activity Assay}

This spectrophotometric assay, measures the free radical scavenging ability of phytochemicals present in the sample. Scavenging of stable DPPH radical renders it colourless, which can be detected at $517 \mathrm{~nm}$. The samples were reacted with DPPH solution prepared in methanol [21]. The absorbance of the DPPH radical was recorded at $517 \mathrm{~nm}$ and the radical scavenging activity of the samples were calculated by the given formula:

\section{\% Radical reaverging activity $=\frac{\text { (Absorbance of control }- \text { Absorbance of sample) }}{\text { Absorbance of control }} \times 100$}

\subsubsection{Detection and Quantification of Phenolic Compounds Using RP-HPLC}

Detection and quantification of various phenolic compounds present in each extract of fresh and dry plant part was done using reverse-phase HPLC (High Performance Liquid Chromatography). Waters HPLC (Model 2487) instrument with a UV spectrophotometer detector was used. The column was a $15 \mathrm{~cm}$ hypersil $\mathrm{C} 18$ reverse phase column with $5 \mu$ particle packing. The mobile phase (Composition $20 \%$ methanol, $1 \%$ acetic acid and $79 \%$ water) was passed through the column at the rate of $1 \mathrm{ml} / \mathrm{min}$.

A linear gradient elution scheme was used in this method and detection was done at $280 \mathrm{~nm}$. The phenolic compounds were identified based on their retention time as identified by a standard chromatogram of a mixture of the pure phenolic compounds obtained beforehand. The concentration of individual phenolic compound was estimated from the peak area measurements and the output was given in the units of $\mathrm{ppm}$. The results were converted from ppm to $\mu \mathrm{g} / \mathrm{mg}$. All the solvents and chemicals used were of HPLC grade.

\subsubsection{Data Analysis}

The mean and standard deviation of the triplicate readings of each sample for each assay were determined and the mean values were analyzed using Microsoft excel. Significant differences between samples were analysed using analysis of variance (ANOVA) with Duncan's Multiple Range Test (DMRT) at $\mathrm{P}<0.05$. Pearson correlation coefficient (R) between different assays i.e. phenolic, flavonoid content and the antioxidant assays was carried out using SPSS software version 19.0.

\section{Results}

In present study, four types of extracts with water, ethanol, methanol, and acetone were prepared from different plant parts. Qualitative as well as quantitative tests were performed on these extracts to assess their phytoconstituents and antioxidant potential.

\subsection{Qualitative Phytochemical Analysis}

Results obtained from qualitative screening of phytochemicals in fresh and dry extracts of Helicteres isora L. are presented in tables 1 and 2. The qualitative tests for various phytochemicals revealed presence of saponins, alkaloids, steroids, terpenoids, glycosides, cardiac glycosides, phenols and flavonoids. The glycosides, phenols and flavonoids were present in all of the 32 extracts tested. Steroids and terpenoids were mainly found in dry plant part extracts whereas only few extracts of fresh plant parts, showed their presence. Tannins were uniquely present in only aqueous extract of dry leaf. Steroids were present in all extracts of dry leaf while present only in aqueous extracts of dry fruit, root, and bark. Out of the four plant parts, dry leaf extracts in four solvents, aqueous, ethanol, methanol and acetone, showed presence of all phytochemicals (Table 2). The fresh plant extracts were found to be low in steroids, terpenoids, and tannins while moderate in saponins and alkaloids. The dry plant extracts were found richer in phytochemicals as compared to fresh ones.

Table 1. Qualitative estimation of phytochemicals in fresh sample extracts of Helicteres isora L. in different solvents

\begin{tabular}{|c|c|c|c|c|c|c|c|c|c|c|}
\hline Plant parts & Solvent & Saponins & Alkaloids & Tannins & Glycosides & Steroids & Terpenoids & Cardiac Glycosides & Phenolics & Flavonoids \\
\hline Fresh & Water & - & - & - & + & - & + & + & + & + \\
\hline \multirow[t]{3}{*}{ leaf } & Ethanol & - & + & - & + & - & - & + & + & + \\
\hline & Methanol & + & - & - & + & - & - & + & + & + \\
\hline & Acetone & - & + & - & + & - & - & - & + & + \\
\hline Fresh & Water & + & - & - & + & - & - & + & + & + \\
\hline \multirow[t]{3}{*}{ bark } & Ethanol & + & + & - & + & - & - & + & + & + \\
\hline & Methanol & + & - & - & + & - & - & + & + & + \\
\hline & Acetone & - & + & - & + & - & - & + & + & + \\
\hline Fresh & Water & - & + & - & + & + & + & - & + & + \\
\hline fruit & Ethanol & + & + & - & + & - & - & - & + & + \\
\hline
\end{tabular}




\begin{tabular}{|c|c|c|c|c|c|c|c|c|c|c|}
\hline Plant parts & Solvent & Saponins & Alkaloids & Tannins & Glycosides & Steroids & Terpenoids & Cardiac Glycosides & Phenolics & Flavonoids \\
\hline \multirow{6}{*}{$\begin{array}{l}\text { Fresh } \\
\text { root }\end{array}$} & Methanol & + & + & - & + & + & + & - & + & + \\
\hline & Acetone & + & + & - & + & - & - & - & + & + \\
\hline & Water & + & - & - & + & - & - & - & + & + \\
\hline & Ethanol & - & - & - & + & - & - & - & + & + \\
\hline & Methanol & - & - & - & + & - & - & - & + & + \\
\hline & Acetone & - & + & - & + & - & - & - & + & + \\
\hline
\end{tabular}

$+=$ present, $-=$ absent

Table 2. Qualitative estimation of phytochemicals in dry sample extracts of Helicteres isora L. in different solvents

\begin{tabular}{|c|c|c|c|c|c|c|c|c|c|c|}
\hline Plant parts & Solvent & Saponins & Alkaloids & Tannins & Glycosides & Steroids & Terpenoids & Cardiac Glycosides & Phenolics & Flavonoids \\
\hline Dry & Water & - & + & + & + & + & + & + & + & + \\
\hline \multirow[t]{3}{*}{ leaf } & Ethanol & - & + & - & + & + & + & + & + & + \\
\hline & Methanol & + & - & - & + & + & + & + & + & + \\
\hline & Acetone & + & + & - & + & + & + & - & + & + \\
\hline Dry & Water & + & + & - & + & + & + & - & + & + \\
\hline \multirow[t]{2}{*}{ bark } & Ethanol & + & + & - & + & - & - & + & + & + \\
\hline & Acetone & + & + & - & + & - & - & - & + & + \\
\hline Dry & Water & - & - & - & + & + & + & - & + & + \\
\hline \multirow[t]{3}{*}{ fruit } & Ethanol & + & + & - & + & - & - & + & + & + \\
\hline & Methanol & + & - & - & + & - & - & - & + & + \\
\hline & Acetone & + & + & - & + & - & - & + & + & + \\
\hline \multirow{3}{*}{$\begin{array}{l}\text { Dry } \\
\text { root }\end{array}$} & Water & + & + & - & + & + & + & - & + & + \\
\hline & Ethanol & - & + & - & + & - & - & + & + & + \\
\hline & Acetone & - & + & - & + & - & - & + & + & + \\
\hline
\end{tabular}

$+=$ present, $-=$ absent

\subsection{Total Phenolic Content (TPC)}

Phenolics or polyphenols are secondary plant metabolites that are most commonly present in plants of high medicinal value. Phenolic compounds contribute to the antioxidant potential of plants by neutralizing free radicals and preventing decomposition of hydroperoxides into free radicals. [22]. The aqueous dry root extract of Helicteres isora L. showed the highest TPC $(7.22 \pm 0.20 \mathrm{mg} / \mathrm{g}$ GAE) among all extracts tested. Moderate phenolic content was found in aqueous extract of dry leaf $(4.57 \pm 0.12 \mathrm{mg} / \mathrm{g}$ GAE$)$.
It was observed that phenolic content was more in extracts of dry plant part as compared to fresh one (Figures 1a and 1b). Fresh root was found to have low phenolic content as compared to all other plant parts. Lowest phenolic content among all extracts tested was found in ethanolic extract of fresh root $(0.73 \pm 1.49 \mathrm{mg} / \mathrm{g} \mathrm{GAE})$. Out of the different solvents that were used to prepare extracts, aqueous extracts were found to have highest phenolic content, while acetone extracts showed lowest TPC values (Figures 1a and 1b).

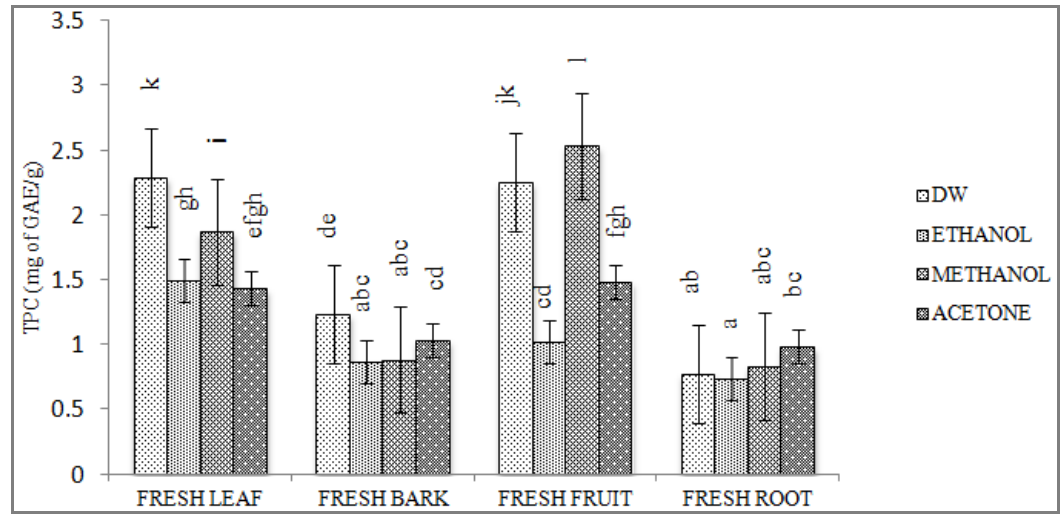

Means followed by different letters differ significantly at $\mathrm{p}<0.05$.

Figure 1(a). Total phenolic content of fresh sample extracts of Helicteres isora (L.) in different solvents. 


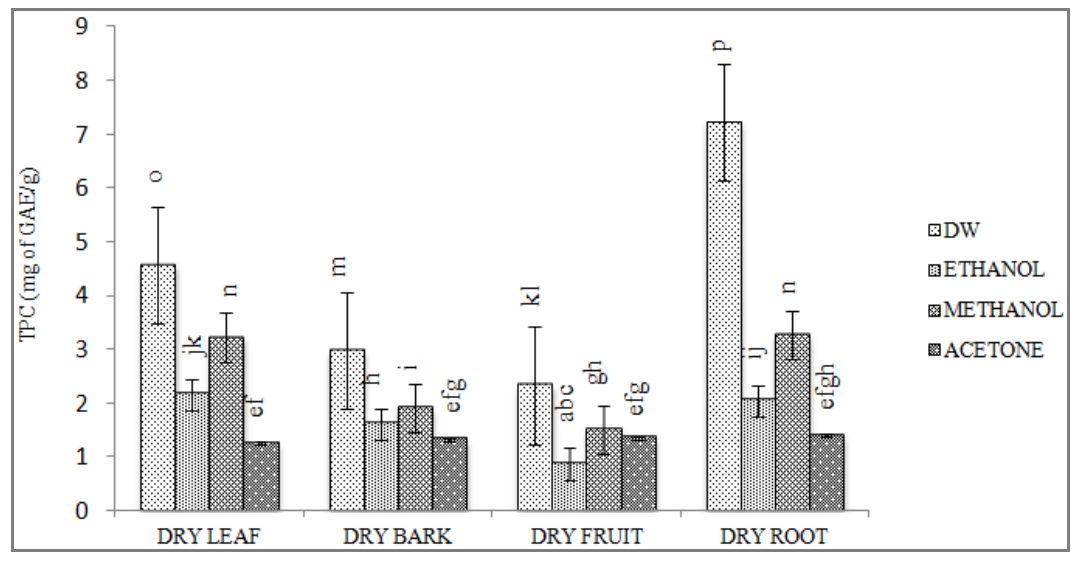

Means followed by different letters differ significantly at $\mathrm{p}<0.05$.

Figure 1(b). Total phenolic content of dry sample extracts of Helicteres isora (L.) in different solvents.

\subsection{Total Flavonoid Content}

Flavonoids are one of the most common and belonging to universally occurring group of plant polyphenolic compounds. Flavonoids are responsible for the radical scavenging effects of most medicinal plants through scavenging or chelating process in vivo as well as in vitro[21].

Within different plant parts, fresh leaves were found to be best source for extracting maximum amount of flavonoids (Fig. 2a and 2b). Highest flavonoids were found in acetone extract of fresh leaf $(57.08 \pm 0.65 \mathrm{mg} / \mathrm{g}$ of RE). In dry bark extracts of Helicteres isora $\mathrm{L}$., TFC values ranged between $11.0 \pm 0.03$ and $5.1 \pm 0.02 \mathrm{mg} / \mathrm{g} \mathrm{RE}$ while fresh bark extracts gave lower TFC values. The TFC values of fresh and dry extracts of fruit and root ranged between $4.05 \pm 0.04 \mathrm{mg} / \mathrm{g} \mathrm{RE}$ and $7.74 \pm 0.32 \mathrm{mg} / \mathrm{g}$ RE except aqueous extract of dry root $(18.60 \pm 0.66 \mathrm{mg} / \mathrm{g} \mathrm{RE})$, which was highest among them. As compared to leaf extracts, other plant parts such as bark, fruit and root showed significantly lower content of total flavonoids (Figures 2a and 2b).

\subsection{FRAP Assay}

Wide range of variation was observed in FRAP values among the plant extracts tested. Highest FRAP values were found in aqueous extracts of dry root $(64.98 \pm 2.58 \mathrm{mg} / \mathrm{g} \mathrm{TE})$ and dry leaves $(53.54 \pm 2.91 \mathrm{mg} / \mathrm{g}$ TE) whereas lowest value was given by acetone extract of fresh bark $(0.33 \pm 5.27 \mathrm{mg} / \mathrm{g}$ TE). Low FRAP activity was observed in all extracts of fresh root ranging from $1.12 \pm 0.24$ and $1.82 \pm 0.61 \mathrm{mg} / \mathrm{g}$ TE. Upon drying, there was a significant increase in FRAP activity in all extracts (Figures $3 a \& 3 b$ ). In each plant part whether fresh or dry, highest FRAP activity was shown by aqueous extracts as compared to ethanolic, methanolic and acetone extracts (Figures 3a \& 3b).

\subsection{DPPH Radical Scavenging Activity}

The quality of the antioxidants in the extracts was determined by the IC50 values, denoting the concentration of the sample required to scavenge $50 \%$ of the DPPH free radicals. It was observed that, DPPH radical scavenging activity of the tested extracts increased with the quantity of plant material in the extract. The results revealed that methanolic extract of fresh fruit was highest in antioxidants among all extracts tested as denoted by the low IC50 value of $34.37 \mathrm{mg} / \mathrm{ml}$. The fresh and dry root extracts showed lowest DPPH radical scavenging activity, as depicted by high IC50 values ranging between 181.05 to $380.10 \mathrm{mg} / \mathrm{ml}$ (figures $4 \mathrm{a}$ and $4 b)$.

\subsection{RP-HPLC Analysis for Phenolic Compounds}

Typical phenolics that possess antioxidant activity are known to be mainly polyphenols, phenolic acids and flavonoid compounds. Phenolics are aromatic benzene ring compounds that have one or more hydroxyl groups. Plants in response to environmental stress and physical injury produce a number of phenolic compounds (Jain et al., 2014). Individual phenolic compounds like Gallic acid, Catechol, Vanillin, Caffeic acid, p-Coumaric acid and Ferulic acid in $H$. isora (Figure 5) were analyzed and quantified using RPHPLC for all the plant extracts. Catechol and Gallic acid were found most abundantly in extracts of $H$. isora (Table 3). Total of 15 extracts showed presence of catechol in $H$. isora in which highest content was found in aqueous extract of dry fruit $(71.0 \mu \mathrm{g} / \mathrm{g})$ whereas aqueous extract of fresh root showed the lowest value $(0.39 \mu \mathrm{g} / \mathrm{g})$ which were comparable to their respective TPC values (Figures $1 \mathrm{~b}$ and 1a). Highest Gallic acid content was found in aqueous extract of dry root $(44.8 \mu \mathrm{g} / \mathrm{g})$ while lowest was found in ethanolic extract of fresh root $(0.38 \mu \mathrm{g} / \mathrm{g})$ which was supported by TPC values of these extracts (Figures $1 \mathrm{~b}$ and 1a). Caffeic acid and Vanillin contents in various extracts ranged between 0.12 to $10.1 \mu \mathrm{g} / \mathrm{g}$ and 0.11 to $25.1 \mu \mathrm{g} / \mathrm{g}$ respectively. It was observed that Ferulic acid was present only in methanolic extract of dry leaf $(8.62 \mu \mathrm{g} / \mathrm{g})$ whereas p-Coumaric acid was found in aqueous extracts of fresh bark $(0.42 \mu \mathrm{g} / \mathrm{g})$, dry bark $(1.0 \mu \mathrm{g} / \mathrm{g})$ and fresh fruit $(4.43 \mu \mathrm{g} / \mathrm{g})$ in $H$. isora.

Aqueous extracts showed the highest extraction capacity for Gallic acid $(44.8 \mu \mathrm{g} / \mathrm{mg})$, Cathechol $(71.0 \mu \mathrm{g} / \mathrm{g})$, Vanillin $(25.1 \mu \mathrm{g} / \mathrm{g})$, Caffeic acid $(10.1 \mu \mathrm{g} / \mathrm{g})$ and $\mathrm{p}$-Coumaric acid $(4.43 \mu \mathrm{g} / \mathrm{g})$ in various explants followed by methanol. Dried 
plant parts such as leaves, bark, root and fruit showed higher amount of phenolics than fresh tissues (Table 3). These

results were supported by TPC analysis (Figures 1a and 1b).

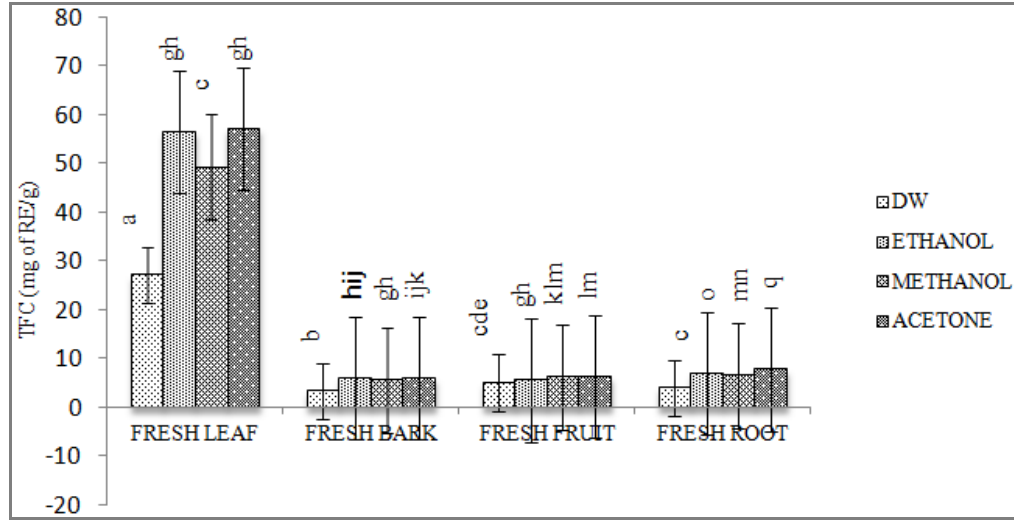

Means followed by different letters differ significantly at $\mathrm{p}<0.05$.

Figure 2(a). Total Flavonoid Content of fresh sample extracts of Helicteres isora (L.) in different solvents

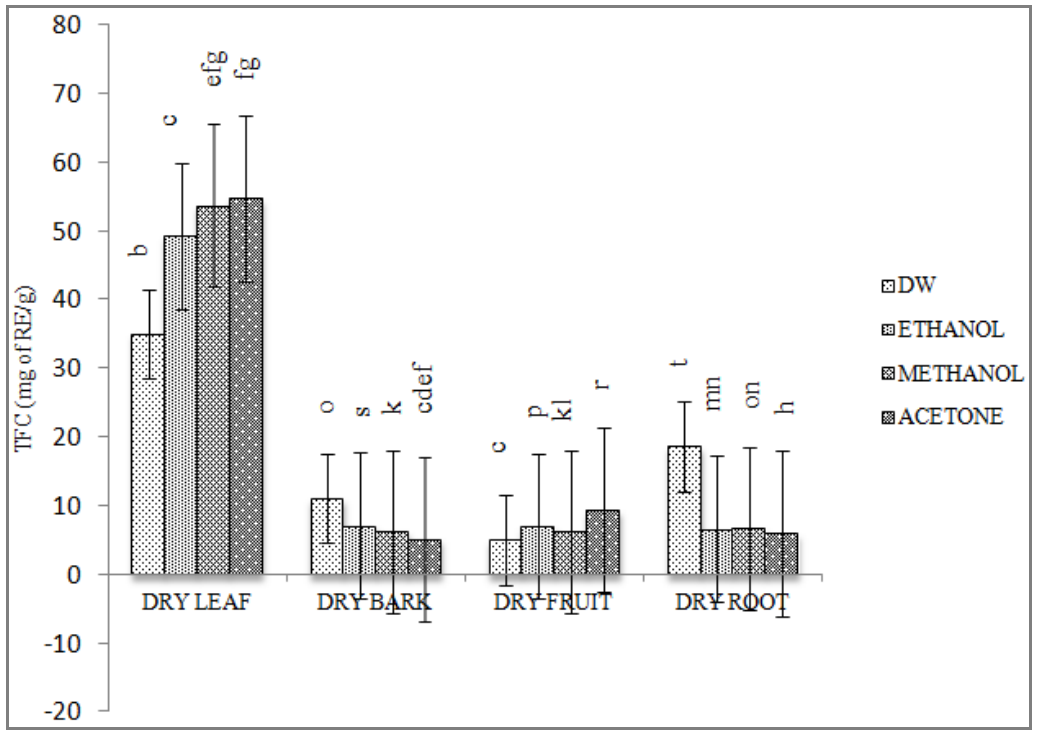

Means followed by different letters differ significantly at $\mathrm{p}<0.05$.

Figure 2(b). Total Flavonoid Content of dry sample extracts of Helicteres isora (L.) in different solvents

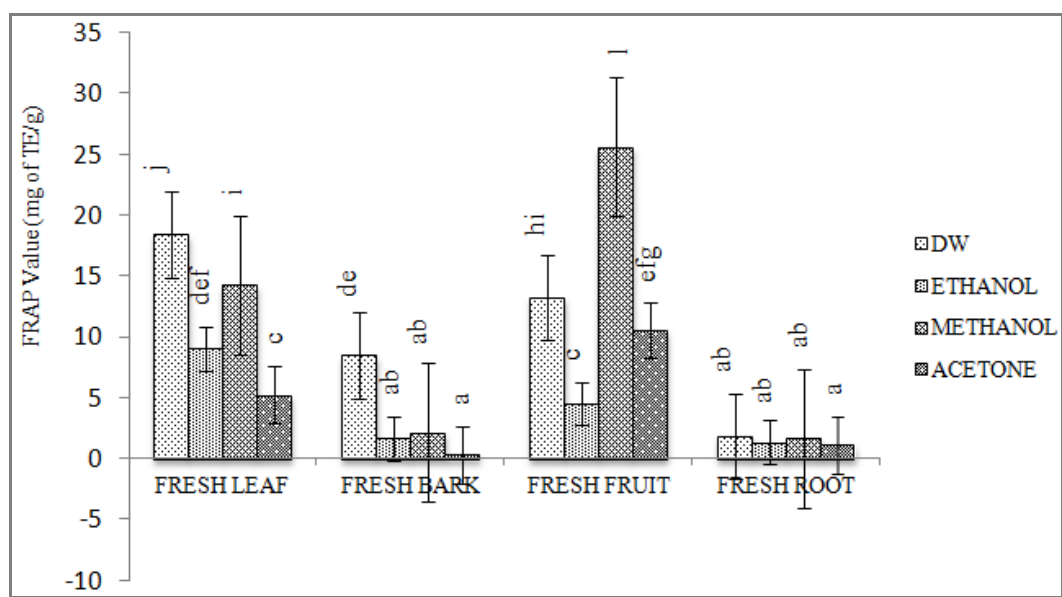

Means followed by different letters differ significantly at $\mathrm{p}<0.05$.

Figure 3(a). FRAP values of fresh samples extracts of Helicteres isora (L.) in different solvents. 


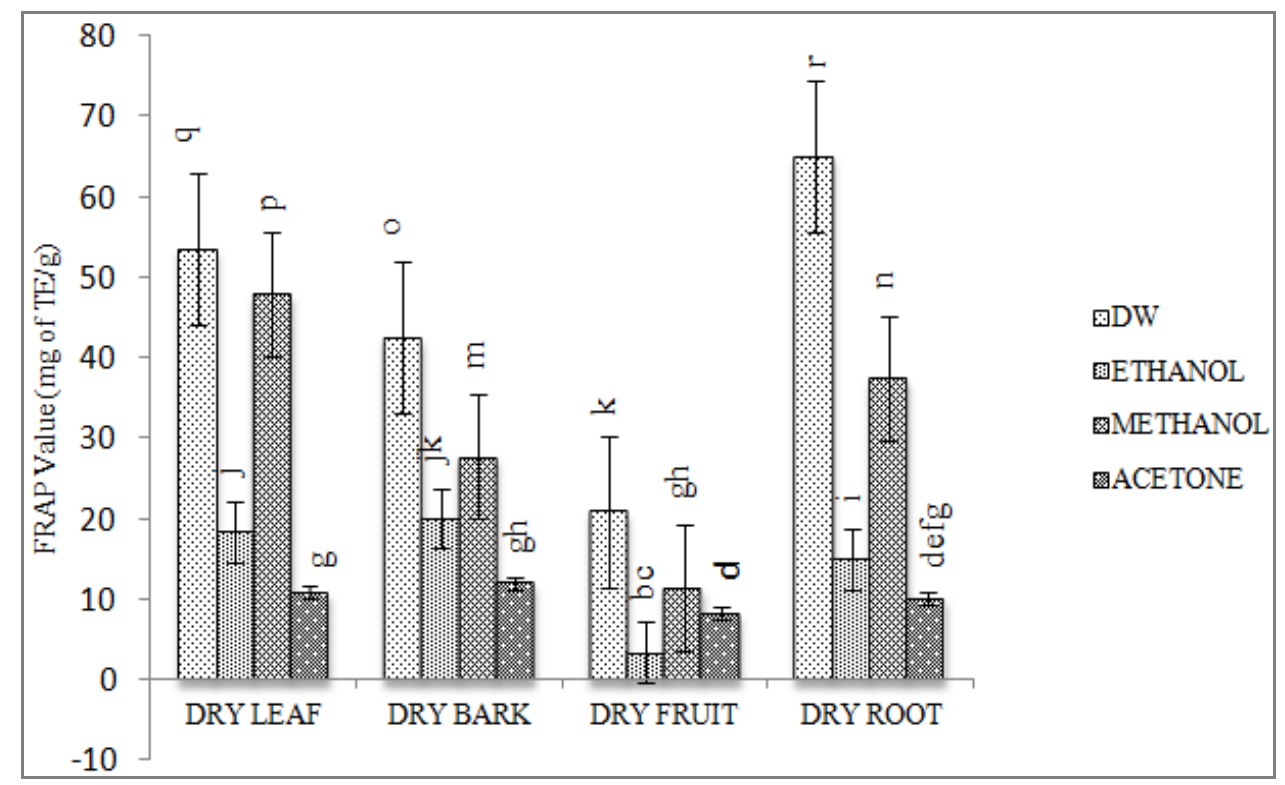

Means followed by different letters differ significantly at $\mathrm{p}<0.05$.

Figure 3(b). FRAP values of dry sample extracts of Helicteres isora (L.) in different solvents.

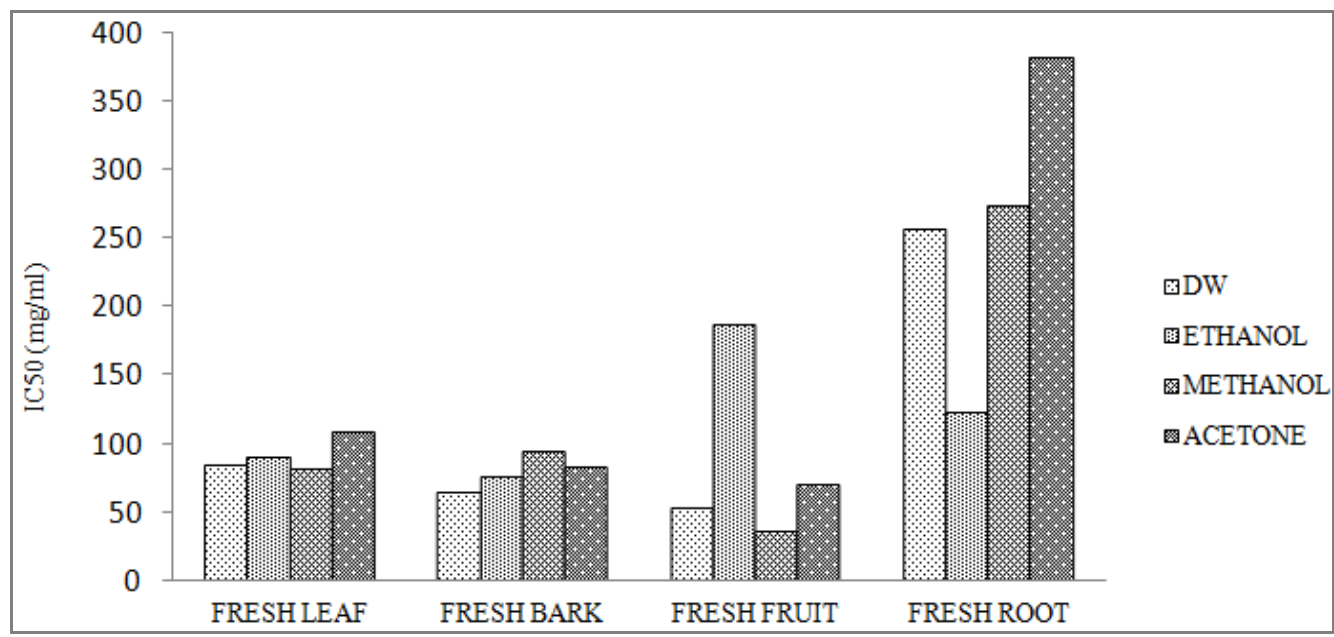

Figure 4(a). IC50 values of fresh sample extracts of Helicteres isora (L.) in different solvents by DPPH free radical scavenging method.

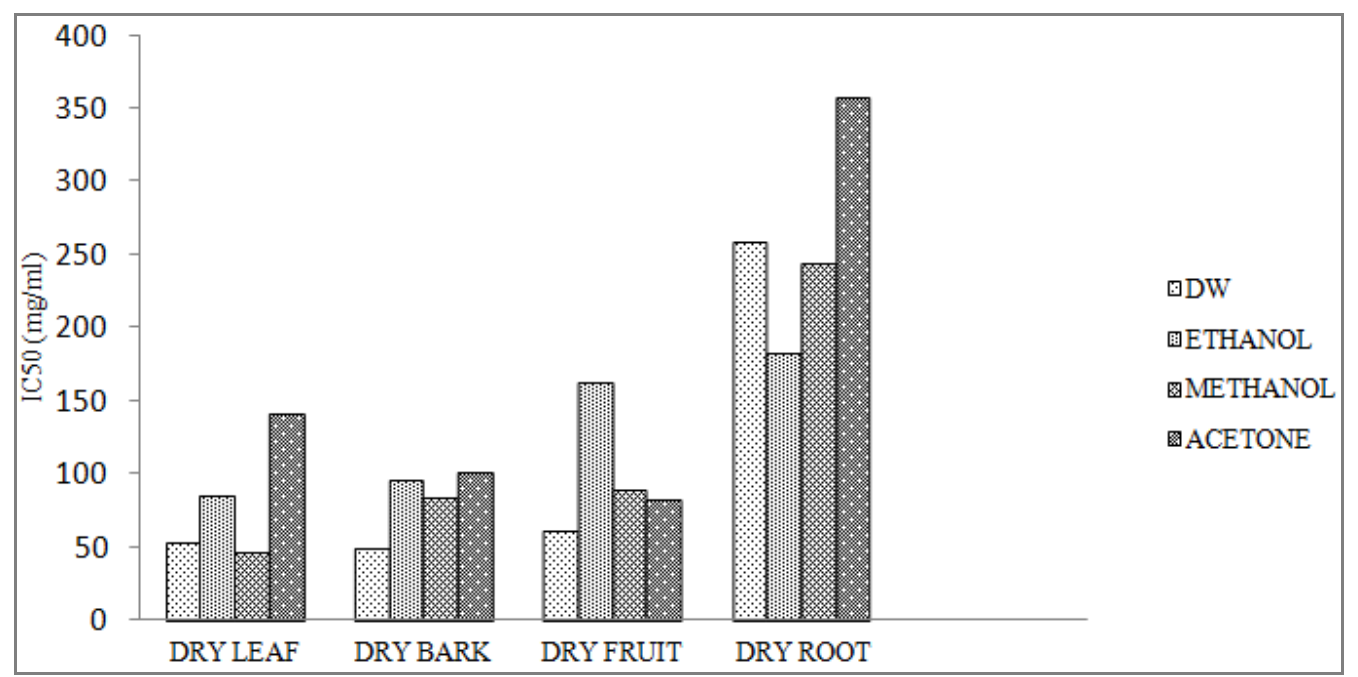

Figure 4(b). IC50 values of dry sample extracts of Helicteres isora (L.) in different solvents by DPPH free radical scavenging method. 
Table 3. Quantification of six phenolic compounds in different extracts of Helicteres isora L. in different solvents by RP-HPLC

\begin{tabular}{|c|c|c|c|c|c|c|c|}
\hline Plant part & Solvent & Gallic acid $(\mu \mathrm{g} / \mathrm{g})$ & Catechol $(\mu \mathrm{g} / \mathrm{g})$ & Vanillin $(\mu \mathrm{g} / \mathrm{g})$ & Caffeic acid $(\mu \mathrm{g} / \mathrm{g})$ & $\begin{array}{l}\text { p-coumaric acid } \\
(\mu \mathrm{g} / \mathrm{g})\end{array}$ & $\begin{array}{l}\text { Ferulic acid } \\
(\mu \mathrm{g} / \mathrm{g})\end{array}$ \\
\hline \multirow{3}{*}{ Fresh leaf } & DW & 2.9 & 2.7 & - & - & - & - \\
\hline & Ethanol & - & - & - & - & - & - \\
\hline & Methanol & - & 14.42 & 3.44 & - & - & - \\
\hline \multirow{3}{*}{ Dry leaf } & DW & 2.5 & - & 0.11 & - & - & - \\
\hline & Ethanol & - & 5.83 & 7.5 & - & - & - \\
\hline & Methanol & - & 6.25 & 6.95 & 0.27 & - & 8.62 \\
\hline \multirow{3}{*}{ Fresh bark } & DW & - & 1.73 & - & - & 0.42 & - \\
\hline & Ethanol & 2.4 & 8.7 & - & - & - & - \\
\hline & Methanol & - & - & 5.32 & 0.23 & - & - \\
\hline \multirow{3}{*}{ Dry bark } & DW & 2.6 & 2.0 & - & - & 1.0 & - \\
\hline & Ethanol & - & 0.45 & - & 0.12 & - & - \\
\hline & Methanol & 2.51 & 1.16 & - & 0.66 & - & - \\
\hline \multirow{3}{*}{ Fresh fruit } & DW & - & 4.0 & - & - & 4.43 & - \\
\hline & Ethanol & - & - & - & - & - & - \\
\hline & Methanol & - & 1.56 & 1.47 & 0.67 & - & - \\
\hline \multirow{3}{*}{ Dry fruit } & DW & 34.0 & 71.0 & 25.1 & 10.1 & - & - \\
\hline & Ethanol & 23.5 & - & - & - & - & - \\
\hline & Methanol & 5.9 & - & 2.4 & - & - & - \\
\hline \multirow{3}{*}{ Fresh root } & DW & - & 0.39 & 0.28 & - & - & - \\
\hline & Ethanol & 0.38 & - & - & - & - & - \\
\hline & Methanol & 2.72 & - & - & 0.30 & - & - \\
\hline \multirow{3}{*}{ Dry root } & DW & 44.8 & 9.17 & - & - & - & - \\
\hline & Ethanol & - & 10.32 & - & - & - & - \\
\hline & Methanol & 42.1 & - & 0.35 & 0.41 & - & - \\
\hline
\end{tabular}

Auto-Scaled Chronatogram

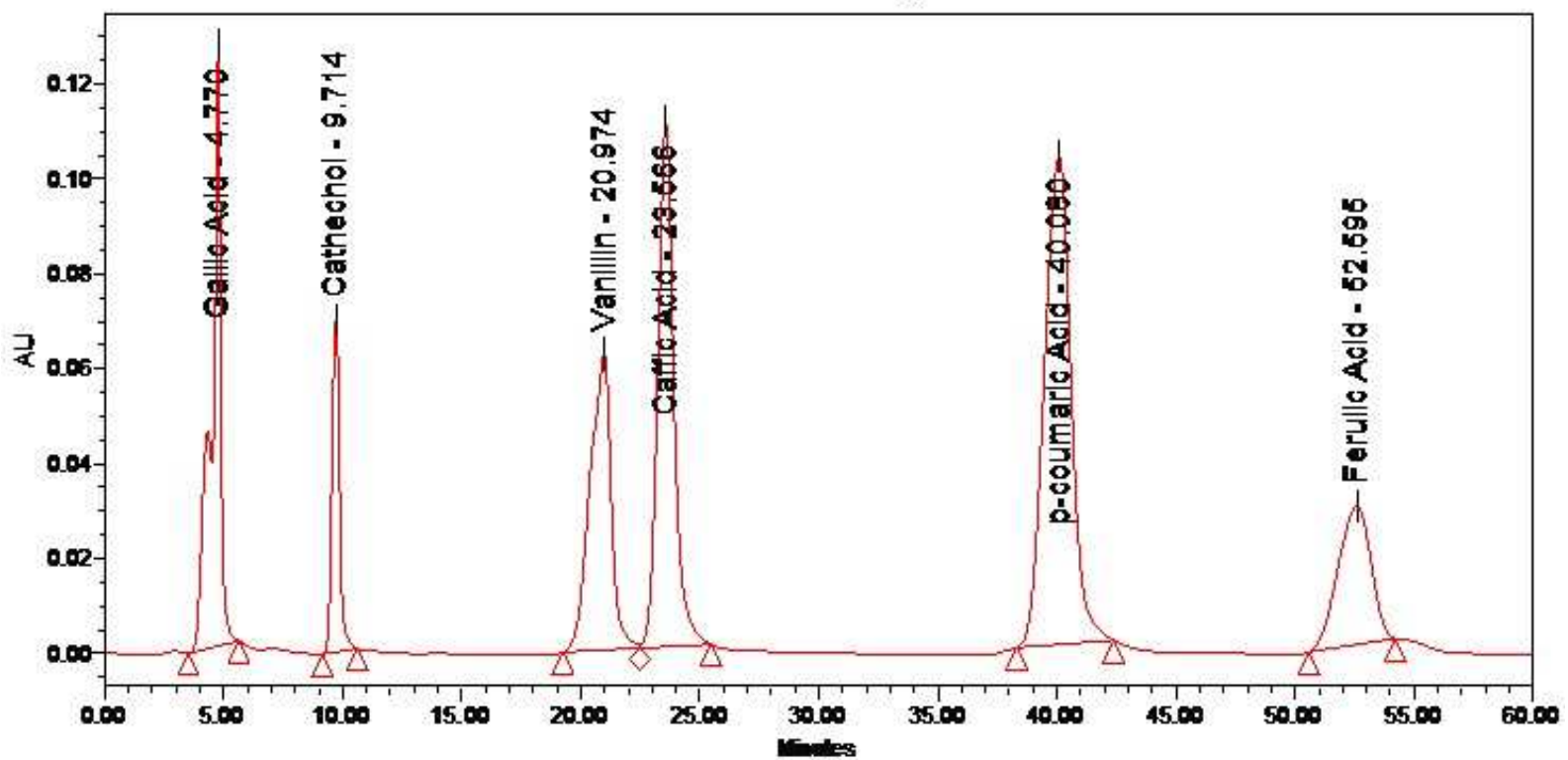

Figure 5. HPLC Fingerprinting: HPLC chromatogram of standard, separated on C18 column (Reverse Phase column $15 \mathrm{~cm}$; particle size 5 um from Hypersil, USA) using gradient elution - Acetic acid, methanol, and water at flow rate of $1 \mathrm{ml} / \mathrm{min}$. The chromatograms of absorbance at $280 \mathrm{~nm}$ were analyzed and compared.

\subsection{Correlation Analysis between TPC, TFC AND Antioxidant Activity (DPPH, FRAP Assay)}

To establish the suitability, reliability and relationship amongst TPC, TFC and free radical scavenging activity (FRAP and DPPH assays), correlation analysis was performed. The Pearson's correlation coefficients (R) for fresh and dry plant parts are given in Table 4.

The total phenolic content showed strong positive correlation with FRAP in both fresh $(\mathrm{R}=0.918)$ and dry $(\mathrm{R}=$ 0.874) plant parts. Similarly positive correlation was observed between TPC and DPPH in fresh and dry $(\mathrm{R}=0.588$ and 0.759$)$ plant extracts. This suggests that phenols are the main compounds responsible for the antioxidant activity 
detected by both FRAP and DPPH assays in Helicteres isora L.

Amongst the two antioxidant assays, FRAP with DPPH has strong positive relation in dry tissues $(\mathrm{R}=0.796)$ indicating relation of high FRAP values to low IC50 values in DPPH assay of dry samples. The results indicate that single assay is not sufficient for the accurate estimation of the total antioxidant capacity and thus a combination of assays should be performed to get better estimate.

Table 4. Correlations (R) between total phenolic content (TPC), total flavonoid content (TFC) and different antioxidant capacity parameters (DPPH and FRAP assays), of H. isora L. fresh and dry plant parts.

\begin{tabular}{|c|c|c|c|}
\hline \multicolumn{4}{|c|}{ Fresh plant parts } \\
\hline & TPC & TFC & FRAP \\
\hline TFC & 0.301 & & \\
\hline FRAP & $0.918^{* *}$ & 0.078 & \\
\hline DPPH & $0.588 *$ & 0.302 & 0.489 \\
\hline \multicolumn{4}{|c|}{ Dry plant parts } \\
\hline & TPC & TFC & FRAP \\
\hline TFC & 0.133 & & \\
\hline FRAP & $0.874^{* *}$ & 0.273 & \\
\hline DPPH & $0.759 * *$ & 0.381 & $0.796 * *$ \\
\hline
\end{tabular}

** Correlation is significant at $\mathrm{P}<0.01$ (2-tailed).

* Correlation is significant at $\mathrm{P}<0.05$ (2-tailed).

\section{Discussion}

The climatic conditions, soil type, nutrition, biotic and abiotic stress etc. influence presence as well as amount of important phytochemicals in medicinal plants [23]. When in vitro studies on phytochemical contents and antioxidant potential in plant extracts are performed, factors such as choice of solvents, method of extraction, type of plant parts and location of collection of plant material, are important factors influencing reproducibility of the results [24]. It was reported by Bhoyar et al. [25] that geographical variation might be responsible for variation in the phytoconstituents of the medicinal plants. We observed that variation occurred in phytochemical content and antioxidant potential of Helicteres isora L. extracts when plants were collected from different locations [19] and the results were compared.

Method of extraction involving drying of plant material influences phytochemical content and antioxidant potential of plant extracts [26]. Different solvents dissolve different biocompounds due to difference in their polarity. The factors affecting the choice of solvent are; quantity of phytochemicals to be extracted, rate of extraction, diversity of different compounds extracted, ease of subsequent handling of the extracts, toxicity of the solvent in the bioassay process and potential health hazard of the extractant [24]. Different parts of medicinal plants are known to contain varying degrees of important phytocompounds and thus their comparative evaluation is necessary in determining the superiority of a particular plant part in terms of medicinal properties [19].

In the present investigation leaf, bark, fruit and root extracts (fresh as well as dry state) of Helicteres isora L. were prepared using water, ethanol, methanol and acetone solvents. Qualitative and quantitative assays were performed to compare the amount of phytochemicals and antioxidant potential in different plant parts extracts prepared in various solvents. Information on change in amount of total phenols, total flavonoids and antioxidant potential of Helicteres isora L. upon drying of plant material before extraction is very limited. Our results clearly indicated that phenolic content and free radical scavenging activity in all plant parts of Helicteres isora L. increase significantly upon drying. Drying of plant material has been reported as useful technique for increasing amount of phenolic compounds and antioxidant capacity of the Larniaceae herb extracts [26].

The qualitative analysis revealed that the dry plant extracts were rich in phytochemicals as compared to fresh ones. The fresh plant extracts were found to be low in steroids, terpenoids, and tannins while moderate in saponins and alkaloids. In the present study, glycosides, phenols and flavonoids were detected in all extracts of $H$ isora. Similar results were shown by $[15,27]$ in $H$. isora.

In present study total phenolic content (TPC), total flavonoid contents (TFC) and free radical scavenging activity of $H$. isora varied among the different plant parts extracted in various solvents. Leaves were rich in flavonoids as compared to other plant parts. Similar results were found in leaves [19] and in fruit and bark [15] of H. isora. TPC assay and RPHPLC showed highest phenolic content in aqueous dry root extract. High antioxidant activity estimated by FRAP assay was also observed in aqueous dry root extracts. However DPPH assay showed that methanolic extract of fresh fruit was uniquely high in DPPH radical scavenging activity with lowest IC50 value $(34.37 \mathrm{mg} / \mathrm{ml})$. Similarly, methanolic extracts of $H$. isora fruits [28,29,30] and blackberry fruits were reported with high free radical scavenging activity [31]. However in previous report of $H$. isora, hot water extract was found to have maximum activity with IC50 value $25.12 \pm 0.18$ $\mu \mathrm{g} / \mathrm{ml}$ in DPPH assay 32.(Suthar et al., 2009). The phenolic compounds were chief phytochemicals responsible for antioxidant properties in Helicteres isora L., as indicated by strong positive correlation between TPC and FRAP, DPPH assays. Similar correlation was found between TPC and antioxidant capacity in the extracts of caper [25], apple [33] and guava [34].

\section{Conclusion}

In the present investigation it was observed that different plant parts of Helicteres isora L. varied in their phytochemical constituents. The high phenolic content was positively correlated with free radical scavenging activity of the extracts. These results were supported by quantitative assays as well as phenolic profiling of extracts using RPHPLC. Although aqueous extract of dry root showed maximum phenolic content and antioxidant potential as observed through TPC and FRAP assay, DPPH radical scavenging activity was exceptionally high in methanolic extract of fresh fruit. This study demonstrated the potency of 
crude aqueous extracts of dry plant parts as significant source of natural phytoconstituents and antioxidant supplements, indicating their strong potential to be used in traditional medicine system.

\section{Acknowledgment}

One of the authors, AJ would like to thank Science and Engineering Research Board, New Delhi for the financial support (FT/LS-130/2012 grant) for this research.

\section{References}

[1] Raja, C. Elanchezhiyan and S. Sethupathy, "Antihyperlipidemic activity of Helicteres isora fruit extract on streptozotocin induced diabetic male wistar rats," European Review for Medical and Pharmacological Sciences, vol. 14, pp. 191-196, 2010.

[2] L. Goldfrank, N. Lewin, N. Flomenbaum and M. Howland, "The Pernicious Panacea: Herbal Medicine," Hospital physicians, vol. 10, pp. 64-86, 1982.

[3] Vulto and P. Smet, "Drugs used in non-orthodox medicine," In Meyler's side effects of drugs, vol.11, pp. 999-1005, 1988.

[4] L. Mentz and E. Schenkel, "A coere^ ncia e a confiabilidade das indicac,o esterape^uticas," Caderno de Farma' cia, vol. 51(2), pp. 93-119, 1989.

[5] F. Ripa, M. Haque and I. Bulbul, "In vitro antibacterial, cytotoxic and antioxidant activities of plant Nephelium longan," Pakistan Journal of Biological Sciences, vol. 13(1), pp. 22-27, 2010.

[6] N. Kumar and A. Singh, "Plant profile, phytochemistry and pharmacology of Avartani (Helicteres isora Linn.): A review," Asian Pacific Journal of Tropical Biomedicine, vol. 4(1), pp. S22-S26, 2014.

[7] G Kumar, G. Banu and A. Murugesan, "Effect of Helicteres isora bark extracts on heart antioxidant status and lipid peroxidation in streptozotocin diabetic rats," Journal of applied biomedicine, vol. 6, pp. 89-95, 2008.

[8] N. Pohocha and N. Grampurohit, "Antispasmodic activity of the fruits of Helicteres isora Linn," Phytotherapy Research, vol. 15 , pp. 49-52, 2001.

[9] K. Singh, S. Saha and J. Maheswari, "Ethnobotany of Helicteres isora Linn. In Kheri district, Uttar Pradesh," Journal of Economic \& Taxonomic Botany, vol. 7(2), pp. 487492, 1985.

[10] G. Kumar, G. Banu, A. Murugesan, and M. Pandian, "Effect of Helicteres isora bark extracts on brain antioxidant status and lipid peroxidation in streptozotocin diabetic rats, Pharmaceutical Biology, vol. 45(10), pp. 753-759, 2007.

[11] T. Kumar, A. Christy, R. Ramya, M. Malaisamy, C. Sivaraj and P. Arjun, "Antioxidant and anticancer activity of Helicteres isora dried fruit solvent extracts," Journal of Academia and Industrial Research, vol. 1(3), pp. 148-152, 2012.

[12] E. Varghese, S. Narayanan, R. Gopal, A. Nair, A. Chittethu and T. Anson, "Anticancer activity of chloroform extract of
Helicteres isora," International Journal of Pharmacy and Technology, vol. 3(2), pp. 2560-2564, 2011.

[13] S. Venkatesh, K. Laxmi, B. Reddy and M. Ramesh, "Antinociceptive activity of Helicteres isora." Fitoterapia, vol. 78(2), pp. 146-148, 2007.

[14] M. Chitra and S. Prema, "Hepatoprotective activity of Helicteres isora Linn. against $\mathrm{CCl} 4$ induced hepatic damage in rats," Hamdard Medicus, vol. 52(1), pp. 112-115, 2009.

[15] P. Gayathri, D. Gayathri, S. Srinivasan and S. Saroja, "Screening and quantitation of phytochemicals and nutritional components of the fruit and bark of Helicteres isora, " Hygeia Journal for Drugs and Medicines, vol. 2(1), pp. 57-62, 2010.

[16] N. Loganayaki, P. Siddhuraju and S. Manian, "Antioxidant activity and free radical scavenging capacity of phenolic extracts from Helicteres isora L. and Ceiba pentandra L," Journal of Food Science and Technology, DOI.10.1007/S 1397-011-0389-x, 2013.

[17] T. Satake, K. Kamiya, Y. Saiki, T. Hama, Y. Fujimoto and S. Kitanaka, "Studies on the constituents of fruits of Helicteres isora L.," Chemical and Pharmaceutical Bulletin, vol. 47(10), pp. 1444-1447, 1999.

[18] P. Ramesh and C. Yuvarajan, "A new flavones methyl ether from H. isora," Journal of Natural Products, vol. 58(8), pp. 1242-1243, 1995.

[19] A. Jain, P. Sinha and N. Desai, "Estimation of flavonoid, phenol content and antioxidant potential of Indian screw tree (Helicteres isora L.)," International Journal of Pharmaceutical Sciences and Drug Research, vol. 5(4), pp. 1320-30, 2014.

[20] S. Ugochukwu, A. Uche and O. Ifeanyi, "Preliminary phytochemical screening of different solvent extracts of stem bark and roots of Dennetia tripetala G. Baker," Asian Journal of Plant Science and Research, vol. 3(3), pp. 10-13, 2013.

[21] V. Pai, S. Sawant, A. Ghatak, P. Chaturvedi, A. Gupte and N. Desai, "Characterization of Indian beers: chemical composition and antioxidant potential," Journal of Food Science and Technology, DOI.10.1007/S 13197-013-1152-2, 2013

[22] S. Chanda and R. Dave, "In vitro models for antioxidant activity evaluation and some medicinal plants possessing antioxidant properties: An overview," African Journal of Microbiology Research, vol. 3(13), pp. 981-996, 2009.

[23] J. Domínguez-Avila, E. Alvarez-Parrilla, G. González-Aguilar, J.Villa-Rodríguez, G. Olivas-Orozco, J. Molina-Corral, M. Gómez-García and L. Rosa, "Influence of Growing Location on the Phytochemical Content of Pecan (Carya illinoinensis) Oil,” Journal of Food Research, vol. 2(5), pp. 143-151, 2013.

[24] P. Tiwari, B. Kumar, M. Kaur, G. Kaur and H. Kaur, "Phytochemical screening and extraction: A review," International Pharmaceutical sciencia, vol. 1, pp. 98-106, 2011.

[25] M. Bhoyar, G. Mishra, P. Naik, and R. Srivastava, "Estimation of antioxidant activity and total phenolics among natural populations of Caper (Capparis spinosa) leaves collected from cold arid desert of trans-Himalayas," Australian Journal of Crop Science, vol. 5(2), pp. 912-919, 2011.

[26] M. Hossain, C. Barry-Ryan, A. Martin-Diana and N. Bunton. "Effect of drying method on the antioxidant capacity of six Larniaceae herbs," Food Chemistry, vol. 123(1), pp. 85-91, 2010 . 
[27] Bilal, C. Elanchezhiyan and S. Sethupathy, "In Vitro antioxidative role of Helicteres isora, " International journal of biomass \& renewable, vol. 01(12), pp.177-183, 2012.

[28] P. Sabale, N. Grampurohit, S. Banerjee, D. Gaikwad and M. Gadhave, "Recent advances on the phytochemical and pharmacological profile of plant Helicteres isora Linn," International Research Journal of Pharmacy, vol. 3(4), pp. 14$16,2012$.

[29] S. Vennila, S. Mohana, G. Bupesh, K. Mathiyazhagan, D. Dhanagaran, M. Baskar, S. Amutha and B. Leeba, "Qualitative Phytochemical screening and in vitro antioxidant activity of Helicteres isora L." Herbal Tech Industry, pp. 14$18,2012$.

[30] B. Polani, P. Krishnamoorthy, N. Deepthi and M. Nissi, "Evaluation of antioxidants and molecular docking studies of Helicteres isora fruit extracts," Journal of Drug Delivery \& Therapeutics, vol. 3(1), pp. 33-35, 2013.

[31] Gawron-Gzella, M. Dudek-Makuch and I. Matlawska, "DPPH radical scavenging activity and phenolic compound content in different leaf extracts from selected blackberry species," Acta Biologica Cracoviensia series Botanica, vol. 54(2), pp. 32-38, 2012.

[32] M. Suthar, G. Rathod and M. Pareek, "Antioxidant and antidiabetic activity of Helicteres isora L. fruits," Indian Journal of Pharmaceutical Sciences, vol. 71(6), pp. 695-699, 2009.

[33] C. Henriquez, S. Almonacid, I. Cheiffelle, T. Valenzuela, M. Araya, L. Cabezas, R. Simpson and H. Speisky, "Determination of antioxidant capacity, total phenolic content and mineral composition of different fruit tissue of five apple cultivars grown in chile," Chilean Journal of Agricultural Research, vol. 70(4), pp. 523-536, 2010

[34] K. Thaipong, U. Boonprakob, K. Crosby, L. Cisneros-Zevallos and D. Byrne, "Comparison of ABTS, DPPH, FRAP, and ORAC assays for estimating antioxidant activity from guava fruit extracts," Journal of Food Composition and Analysis, vol. 19, pp. 669-675, 2006. 